\title{
Maestros en relación: Río de la Plata (década de 1820)
}

Teachers in Context: Río de la Plata (1820s)

\section{José Bustamante Vismara}

Conicet/Universidad Nacional de Mar del Plata

jovisma@hotmail.com

\begin{abstract}
Resumen
Los trabajos de historia de la educación argentina que atienden a la primera mitad del siglo XIX suelen estar encuadrados en recortes institucionales. Se detienen en apreciar los momentos fundacionales de las escuelas, reproducen las formulaciones que determinados gobiernos expresaron acerca del tema o transitan las obras que los pedagogos redactaron sobre la educación, pero pocos textos reconocen y analizan a quienes enseñaron y el contexto en que lo hicieron. Aquí el objeto de análisis son los maestros de escuelas de primeras letras, atendidos en relación con curas, funcionarios estatales, colegas, vecinos o padres. En torno a ellos, ciertos aspectos relacionales son destacados mediante el concepto de "configuración escolar". Tal es la perspectiva metodológica con la que se estudia lo ocurrido en la ciudad y la campaña de Buenos Aires en 1820
\end{abstract}

Palabras clave: historia de la educación, maestros, configuración escolar, Buenos Aires, 1820.

\section{Abstract}

Research on the history of education in Argentina in the first half of the nineteenth century usually focuses on the institutional level. Most works examine the founding moments of schools or repeat what governments expressed on various issues, but few stop to acknowledge those who taught and the context in which they did it. In this article, school teachers are the object of analysis. Teachers are seen in relation to priests, state officials, colleagues, neighbors or parents, and their links are highlighted by means of the concept of "school configuration". That is the methodological perspective employed to examine what happened in both the city and the countryside of Buenos Aires in the 1820s.

Keywords: history of education, teachers, school configuration, Buenos Aires, 1820 


\section{Introducción}

Hombres dedicados a la enseñanza elemental durante el periodo posindependiente; varones que ejercieron en establecimientos financiados por el Estado. He aquí el objeto de análisis de este artículo. Una historia de letrados, que estuvieron lejos de ser miembros de la élite letrada. Y que buscaron, en algún momento de su vida, desempeñarse al frente de escuelas de primeras letras. ${ }^{1}$

Para abordar este asunto, se aludirá al perfil de los educadores y las escuelas donde se desempeñaron, pero el énfasis estará puesto en los modos en que ellos se relacionaron con otros actores sociales. Con tal propósito, el concepto de "configuración escolar" intenta ser puesto en uso. La noción se articula con el desarrollo teórico de Norbert Elias. En La sociedad cortesana (1993) y en El proceso de la civilización (1987) el sociólogo alemán empleó el concepto para describir procesos de sociogénesis e internalización de conductas en miradas de largo plazo. Esa propuesta fue resignificada por Elsie Rockwell (2007) para el análisis de la educación posrevolucionaria en Tlaxcala, México. Ella lleva adelante una argumentación en la que lo antropológico y lo histórico se enlazan. En su trabajo recupera la idea de "configuración" y la estrecha al marco cultural y escolar. Si bien lo hace en un contexto social y político diferente al que se atiende en este artículo, el concepto de "configuración escolar" permitiría dar cuenta de aspectos relacionales y atender contingencias. ${ }^{2}$ Así, cambios o reacomodos que no están preestablecidos por una lógica institucional o estructural, esperan ser interpretados. De este modo, junto a una rica y variada evidencia documental sobre contextos situados en los que se insertaba a los maestros, el término "configuración escolar" servirá de malla para darle sentido de conjunto a las diferentes relaciones atendidas. Se trata de una herramienta para evaluar el modo en que aspectos sociales locales dan sentido a la construcción institucional o estatal. Así, lo educativo no es mero reflejo de las políticas de los estados posindependientes, sino también de las recreaciones cotidianas que en torno a éstas generaron los involucrados.

Este marco se emplea para un análisis que no sesgue esta historia de maestros en el recuento de las acciones que unos pocos y prominentes pedagogos llevaron adelante, o bien que sus referencias sirvan para marcar un contrapunto entre un lejano ideario y la realidad en que vivieron. Las tramas que aquí se reconstruyen buscan ser puestas en contexto, recreando las condiciones en que determinadas prácticas se desarrollaron, así como se inten-

\footnotetext{
${ }^{1}$ Acerca del concepto escuela de primeras letras y sus vínculos con la categoría escuela pública, véanse Martínez y Bustamante (2014)

2 Esta interpretación del concepto de "configuración escolar" no tiene un lugar destacado en la completa y estimulante antología de textos que se ha reunido de la obra de Rockwell (2018). Más precisamente, en los distintos artículos allí compilados, se alude con mayor énfasis a "configuraciones culturales" que a las limitadas por el ámbito escolar.
} 
tan reconocer las interacciones en que cobraron forma. Con tal propósito, se organizará el artículo en apartados en los que los maestros son ligados al contexto en que se desempeñaron, se les aprecia en diálogo con padres y alumnos, con vecinos, sacerdotes y autoridades civiles, y - hacia el final- se reconstruyen los vínculos sucedidos en la Academia de Preceptores. Se trata de una historia de la educación reconocida como "práctica local"; esto es, recuperando las condiciones locales de su producción e interacción con las comunidades específicas. Con ello se espera poner en tensión las miradas más tradicionales acerca del tema.

A pesar de la rica renovación historiográfica que desde la historia rural y política se ha producido acerca del periodo en Buenos Aires y su campaña, lo educativo no ha sido un objeto frecuente de investigación. No obstante, hay trabajos sobre dicha temática, desde los cuales cobra sentido la siguiente indagación. García Belsunce (1979) editó un estudio que atiende a las escuelas y sus maestros, pero lo hace a partir de algunos presupuestos que aquí son discutidos: considera dichas escuelas como parte de un sistema; alude a un supuesto traspaso de una educación en manos de la Iglesia a otra, gradualmente secularizada; enmarca estas referencias en un plano nacional. Las precisiones metodológicas y conceptuales que ofreció Newland (1992) resultan esclarecedoras, pero en su trabajo se opacan algunas distinciones que cabe reconocer entre la ciudad y el campo, y no se considera a los maestros en tanto particular objeto de análisis. Narodowski (1999), por su parte, se detuvo sobre lo ocurrido en torno al sistema lancasteriano y la presencia de un cuerpo de especialistas en lo pedagógico. Mientras que Bustamante (2007) —donde sí se focalizó en la campaña e incluyó un capítulo acera de los maestros - lo hizo desde una perspectiva de largo plazo, en la que no se ofrecía una conceptualización teórica al respecto. En conjunto, el periodo se ha enriquecido gracias a diversos estudios que han aportado valiosas líneas de interpretación. Más allá de estas notas, los trabajos citados constituyen un punto de referencia clave, en contraposición a la marginalidad a la que suele relegarse el periodo en la disciplina. Es sabido que, en torno a la historia de la educación argentina, hay un fuerte énfasis por visualizar lo sucedido hacia fines del siglo XIX.

¿Y por qué acotar la perspectiva a lo sucedido en la década de 1820? Tras la crisis de la monarquía española y la revolución de 1810, el territorio que había ocupado el virreinato del Río de la Plata atravesó por diversos ensayos políticos. Hacia 1820, los intentos que habían buscado la unidad o el centralismo habían fracasado, e iniciaron experiencias políticas autónomas. En ese contexto, la provincia de Buenos Aires, entre otras, emprendió un profundo proceso de cambios: se abolieron los cabildos, se conformó una sala de representantes, se reformó el clero, comenzó a emitirse papel moneda, se promulgó una ley de sufragio electoral relativamente amplia. Mientras que desde la esfera de la producción la expansión ganadera y la exportación de cueros conllevó renovadas bases de riqueza. 
El conjunto de esas iniciativas tuvo un trasfondo republicano que se articuló al caudi\|lismo. La historiografía social y política ha ofrecido renovadores acercamientos acerca de esas estas reformas y de los procesos institucionales que condujeron al ascenso de Juan Manuel de Rosas a la gobernación (entre 1829 y 1832, primero, y entre 1835 y 1852, después). ${ }^{3}$ En ese horizonte, las referencias a lo educativo suelen centrarse en la erección de la Universidad de Buenos Aires en 1821 y poco se alude a la educación elemental. Se trata, sin embargo, de un periodo en el que las escuelas financiadas por el Estado crecieron notablemente y, con éstas, se incrementó la demanda de maestros. En ese marco -y quizás ésa sea una especificidad del periodo- hombres que no habían transitado por una escuela se lanzaron a ocupar un cargo en las mismas.

Un aspecto adicional se deriva de la perspectiva limitada a lo sucedido durante una década: por un lado, en lugar de narrar etapas y procesos de cambio, se han privilegiado las singularidades de una década; con ello se pretenden situar las condiciones en que se desarrollan las interacciones. Y, por el otro, se busca eludir el dejo teleológico que pudiera suponer un análisis que enfatice cambios o continuidades a lo largo de un periodo más extenso. ${ }^{4}$

Las fuentes en que se sustenta este análisis provienen, fundamentalmente, del Archivo General de la Nación y del Archivo Histórico de la Provincia de Buenos Aires, ubicados en Buenos Aires y La Plata, respectivamente. Se trata de legajos, expedientes y oficios de diversa naturaleza. Incluyen formulaciones prescriptivas, pero también dan cuenta de cómo circularon esas prescripciones, refieren a los modos en que los padres o vecinos consideraban a los maestros, aluden a reclamos o demandas de la comunidad educativa. Como fruto del análisis, se espera abordar diversas interrogantes: ¿hasta qué punto puede sostenerse el lugar que reconoce a los clérigos en estrecho contacto con las tareas de enseñanza elemental? ¿Cómo se caracterizarían los vínculos entre los propios maestros? ¿Y de ellos con las autoridades estatales? ¿Es posible reconocer instancias en las que los maestros sean reconocidos en tanto grupo?

\section{Maestros y preceptores en escuelas públicas del periodo posindependiente}

Maestros y preceptores fueron vocablos que aludieron a un mismo tipo de ocupación. ${ }^{5}$ No se aprecian rasgos que los distingan. Las menciones a profesores o al magisterio sólo se lo-

\footnotetext{
${ }^{3}$ Entre otros trabajos, pueden citarse los realizados por Ternavasio (2002), Aliata (2006) y Fradkin (2008).

${ }^{4}$ En el trabajo que publiqué en 2007, al compás del esfuerzo por explicar los procesos de cambio sucedidos entre 1800 y 1860, se traslapa cierto telón de fondo teleológico que ha sido, no sin razón, observado.

${ }^{5}$ Para un acercamiento conceptual a la temática, véase Roldán (2014).
} 
calizan en contextos muy precisos, que no suelen estrecharse con la educación elemental, mientras que no se encuentran referencias a doctrineros o docentes. Algunos aspectos generales sobre sus perfiles y el modo como desarrollaron sus actividades en la ciudad y en la campaña de Buenos Aires son referidos en este primer apartado.

Ambas regiones conocieron, a lo largo de la década de 1820, un paulatino crecimiento de los servicios educativos financiados por el Estado. Las escuelas de primeras letras tuvieron una activa presencia tanto en el campo como en la ciudad. En ésta se sostuvieron con cierta regularidad alrededor de diez establecimientos. En los pueblos de la zona rural, el número de establecimientos se incrementó en forma significativa a lo largo de la década señalada. ${ }^{6}$ Aunque con intermitencias, cada uno de los poblados de la campaña de Buenos Aires llegó a tener una escuela de primeras letras (a las que se sumarían establecimientos con otro tipo de administración). Esa expansión no se limitó al periodo rivadaviano, ni fue cortada con la primera gobernación de Rosas.

El horizonte institucional referido supuso distintos desafíos; además del financiamiento y de la generación del consenso requerido para que los niños asistieran a las escuelas, se debió contratar un número significativo de preceptores. En un contexto usualmente caracterizado por la escasez de mano de obra y en el que la enseñanza no estaba afirmada como alternativa laboral, la provisión de maestros constituyó un reto.

En las prescripciones sobre el perfil de los maestros, se enfatizan aspectos ligados a las buenas costumbres y el honor de los candidatos. Su acreditada moralidad y pública práctica del catolicismo tenían un lugar destacado, incluso más relevante que la pericia en las materias que debían enseñarse. Los aspectos pedagógicos sólo tuvieron alguna importancia —-como se verá más adelante - en el marco de la propagación del sistema de enseñanza mutua; fuera de ese contexto, no parecieron ser relevantes. Generalmente el candidato se postulaba con alguna carta de recomendación, eventualmente un maestro distinguido efectuaba una evaluación del postulante (Bustamente, 2007b).

La administración de estas escuelas conoció cierta centralización a partir de dos reglamentos expedidos en 1816 y 1818. Allí se designaba un director o inspector general que coordinara el ramo. Entre 1821 y 1827, esas autoridades y sus gestiones se articularon al Departamento de Primeras Letras de la Universidad de Buenos Aires; mientras que, a partir de 1828, el inspector general de escuelas pasó a depender, directamente, del Ministerio de

\footnotetext{
${ }^{6}$ En 1827 en la ciudad funcionaban escuelas en los siguientes barrios: Concepción, San Telmo, Merced, San Nicolás, Socorro, Barracas, Hospicio, Recoleta, Monserrat, Piedad. Y los pueblos de la campaña que tenían escuela de varones sostenida por el Estado eran Carmen de Patagones, San José de Flores, San Fernando, San Isidro, Morón, Las Conchas, Chascomús, Quilmes, Santos Lugares, Ensenada, San Vicente, Capilla de Merlo, San Antonio de Areco, Magdalena, Pergamino, Exaltación de la Cruz, Cañuelas, Villa del Luján, Pilar, Baradero, Arrecifes, Lobos, San Pedro, Navarro, Rojas, Guardia del Luján, Guardia del Monte, San Nicolás de los Arroyos, Areco y Ranchos. Sala X-6-2-5, Archivo General de la Nación, Buenos Aires (en adelante AGN, Buenos Aires). Sobre el tema, véase Bustamante (2007a).
} 
Gobierno del Estado de Buenos Aires. Desde allí se gestionaban los pagos a los maestros, el envío de útiles, la refacción o compra de casas para escuelas. Además, aquellas autoridades fiscalizaron con cierta cercanía lo sucedido en las escuelas de la ciudad, pero en los pueblos de la campaña la supervisión de los establecimientos fue delegada en juntas protectoras, presididas por el juez de paz del poblado, quien era acompañado por algún clérigo y uno o dos vecinos?

Los maestros porteños tuvieron visitas esporádicas del prefecto o del director de Educación; incluso el Departamento de Escuelas contaba con un auxiliar u ordenanza que repartía oficios y comunicaciones entre los establecimientos. Y los desempeños de los preceptores fueron evaluados en certámenes o exámenes. En la ciudad hubo presentaciones a las que debían acudir los preceptores, junto a sus alumnos más destacados. Así, por ejemplo, en 1825, el rector de la universidad, Antonio Sáenz, solicitó fondos para premiar a los alumnos que sobresaliesen en las funciones públicas del día 20 de mayo. Por medio de la evaluación de los alumnos más adelantados se buscaba "dar pruebas al público de que la enseñanza de primeras letras produce adelantamientos y ventajas en los niños que frecuentan las escuelas". 8

Con tal propósito, el ministro García aprobó la erogación de \$200 para la composición de medallas como "premio a la aplicación". Estas presentaciones, asociadas a los festejos de mayo, se repetirían. En mayo de 1828, Saturnino Segurola envió una circular a los maestros de la ciudad para que al celebrar el aniversario de "nuestra reorganización pública" se presentaran con sus alumnos en el patio de la escuela normal para, desde allí, dirigirse a la plaza de la Victoria. ${ }^{9}$ En estas presentaciones públicas, lógicamente, se articulaba la examinación a los alumnos y a los maestros, con la celebración de las fiestas patrias.

En la campaña el visado de las actividades de los maestros debía ser regularmente evaluado por las juntas protectoras. Rara vez ello sucedía con la periodicidad sugerida en los reglamentos. La escuela de Pergamino mostró un caso atípico, uno de los miembros de la junta informaba: "habiendo visitado mensualmente la oficina de la enseñanza pública de primeras letras en los cinco meses corridos desde el primero de enero del corriente año hasta esta fecha ha observado siempre el buen orden y disciplina escolar". 10 Y menos usual fue la visita de un prominente personaje de la dirigencia estatal. El paso de Juan Manuel de Rosas en 1830 por algunos pueblos de la campaña y sus escuelas no pasaría desapercibido. Así lo hizo el maestro Lorenzo Calderón quien informó que el gobernador, tras visitar el

\footnotetext{
${ }^{7}$ Tal composición colegiada traería como correlato una producción de legajos y documentos que contrasta con la limitada información acerca de los establecimientos de la ciudad.

${ }^{8}$ Sala X-6-2-4, ACN, Buenos Aires. La ortografía de las citas ha sido actualizada.

${ }^{9}$ Expediente 630, legajo 7, Dirección General de Escuelas, Archivo Histórico de la Provincia de Buenos Aires, La Plata (DGE, AHPBA, La Plata).

${ }^{10}$ Expediente 1196, legajo 16, DGE, AHPBA, La Plata.
} 
convento de San Pedro, se dirigió a la escuela y le refirió que para el día siguiente "tuviese prontos a los niños para conocerlos". Hacia las nueve y media de la mañana del día siguiente se presentó "los hizo persignar a todos, y les preguntó la doctrina y hallándolos a todos indebidamente expertos en la tarea escripturaria [sic], y en la doctrina, en una vía progresiva". Tras su partida envió 4 reales a cada niño y ordenó que se les diera asueto por el resto del día. El maestro, a la vez que informaba a Segurola sobre este resultado, se congratulaba por la actuación de los alumnos.

\section{Maestros, alumnos y padres}

El modo más extendido en que los maestros aluden a los niños los distingue por sus inasistencias. Abundan las referencias a los jóvenes que nunca pisaron la escuela o bien que se caracterizaron por una errática presencia. Y allí se diluye la estela de la mayor parte de los niños. Aquellos que sí pasaron por las aulas pocas veces lo hicieron regularmente. Es sensato considerar que la irregularidad haya sido mayor en la zona rural que en la ciudad. Desde San Isidro se ofrece un reconocimiento del asunto, indicó el juez de paz en 1826: "en la campaña no hay los recursos que en la ciudad para la concurrencia a la escuela. Su distancia, malos caminos, sin veredas, el rigor del frío, poco abrigo, el calor demasiado teniendo que transportarse a campo raso impide muchas veces la concurrencia; estorbos que en lo general no los hay en la ciudad"."

La actividad escolar tenía un horario desdoblado. Los alumnos debían presentarse unas horas por la mañana y otras por la tarde. Eso exigía por parte de los maestros una dedicación a tiempo completo. Como refirió el preceptor Ángel López del Campo en abril de 1829: si bien los alumnos se han ausentado con frecuencia, "puedo decir que no he faltado un solo día mañana y tarde". ${ }^{2}$ Los asuetos se pautaban por las celebraciones litúrgicas y el calendario patriótico. Así, salvo licencias o permisos puntuales, no existía un periodo de descanso. Las vacaciones fueron periodos determinados por las condiciones laborales impuestas por las cosechas o los trabajos rurales.

El trato entre maestros y alumnos en las primeras décadas del siglo está teñido por lazos desiguales. Esta general valoración, ¿qué formas cobró en la cotidianidad escolar? No faltaron referencias en las que los involucrados aludieron al cariño y la estima. Joseph Bucault distinguía a los niños como "tiernos paisanitos"; Juan Pablo Márquez renunciaba a su cargo de preceptor en Chascomús en 1827 por lo corto del pago, aunque los padres de los niños

\footnotetext{
${ }^{11}$ Expediente 229, legajo 3, DGE, AHPBA, La Plata.

12 Expediente 672, legajo 7, DGE, AHPBA, La Plata.
} 
lo lamentaban, en virtud de la manera amable y el tacto fino que tenía con los niños. ${ }^{13}$ Incluso algunas de las disposiciones oficiales referían que los preceptores debían tratar con "amor y liberalidad" a sus discípulos, "sin oprimirlos despóticamente". ${ }^{14}$

Una apreciación alternativa de los vínculos entre maestros y alumnos se reconoce a través de los castigos; los cuales fueron prohibidos en distintas reglamentaciones de la década de 1810.15 Pero esas prescripciones no siempre fueron cumplidas. En 1830, el maestro de Monte, Manuel Cayetano Rodríguez, envió una carta al inspector general explicándole que le había dado cuatro azotes a un niño. ¿Por qué? Hacía nueve días que no le daba lección, lo desobedecía, interrumpía y hasta llegó a amenazarlo. Tras el castigo, la madre del niño irrumpió en la escuela insultando al maestro "del modo que quiso". 16 Para colmo de males, el alumno era el hijo del juez de paz. La carta que enviaba Rodríguez pretendía anticipar las noticias que, seguramente, el inspector recibiría. Y al anoticiarlo justificaba su proceder:

me parece que en la escuela no hay distinción. Aunque es verdad que he desobedecido al reglamento, pero en la campaña es necesario mostrarse algo serio, porque hay niño que no le hacen mella las expresiones. Es el primero que reprendo de esta manera, y si lo hice fue porque era preciso, yo he sido amenazado, diciéndome que se me ha de quitar el empleo ¡señor! Si es cosa así que me han de hacer pasar un bochorno de esa manera será mejor que VE me avise para con tiempo dejarlo antes que me lo quiten. ${ }^{17}$

Rodríguez afirmó que los azotes tenían sentido al garantizar la autoridad, en su escuela no debía haber distinción. Además, consideró que en la campaña la generalizada rudeza permitía un umbral de violencia que sería inadmisible en la ciudad. Un detalle adicional: el juez de paz no parece haber elevado ninguna queja sobre los castigos del maestro. Y éste continuó desempeñándose hasta febrero de 1832, cuando huyó del pueblo dejando la llave de la escuela en poder de la manceba con la que hasta entonces vivía. ${ }^{18}$

Desde un plano diferente, se aprecia el modo en que se entablaban los vínculos entre maestro, alumno y castigos en la ciudad. En 1826, el prefecto del Departamento de Primeras Letras recibió una crítica carta de un padre llamado Tomás Mota, quien enviaba a su hijo de ocho años a la escuela particular de don Francisco Molina. Según las palabras de Mota, el

\footnotetext{
${ }^{13}$ Sala X-6-2-5, ACN, Buenos Aires. Tras estas referencias, los padres y vecinos del poblado señalaron que colectarían un adicional para que el maestro se mantuviera en el puesto.

${ }^{14}$ Expediente 16, Sala X-6-1-1, AGN, Buenos Aires. Véase, particularmente, el artículo $3^{\circ}$ del reglamento.

${ }^{15}$ Más allá de la conocida prohibición de la Asamblea del año XIII, la policía hizo circular por Buenos Aires un impreso en la que se difundía la prohibición de los castigos mediante azotes. Sala X-32-10-1, ACN, Buenos Aires.

${ }^{16}$ Expediente 734, legajo 9, DGE, AHPBA, La Plata.

${ }^{17}$ Expediente 734, legajo 9, DGE, AHPBA, La Plata.

${ }^{18}$ Expediente 900, legajo 11, DCE, AHPBA, La Plata.
} 
maestro "desahogó su brutal rabia" sobre el alumno, debido a "un leve descuido, o distracción". De resultas de ello, dijo el padre, "tuve la más dolorosa sorpresa al ver mi hijo [...] en un estado capaz de enternecer a los más indiferentes, cubierto de cardenales de pies a cabeza y aturdido aun del horroroso castigo". ${ }^{19}$ El niño quedó en cama un par de días y habría intervenido la policía. La nota del padre cierra con una reflexión sobre el tema que aquí interesa, indica: "El derecho transmitido a un Maestro por un Padre de familia no se extiende a semejantes arrebatos, o violencias de carácter [...], guardándose de maltratar tiernos infantes que sólo se le confían para enseñar en lo posible con la paciencia y el estímulo".

El papel de los maestros buscó actualizar, fuera del hogar, el lugar del padre. Su buen nombre debía ser respetado y sus mandatos aceptados por los discípulos. Sin embargo, esa autoridad no fue fácilmente cimentada, y para ponderar tal valoración puede resultar explicativo atender al modo en que se vincularon con otras autoridades del periodo. Antes de proseguir con ello, cabe detenerse en las caracterizaciones referidas acerca de los castigos para afirmar un tipo de vínculo bastante predecible: la asimétrica relación existente entre alumnos y maestros. Por más que estos últimos tuvieran una endeble autoridad y carecieran de preparación profesional, la relación con los niños estuvo articulada por paternalismo y violencia. Aunque es posible afirmar que son pocos los datos que pueden recogerse acerca del vínculo - escasos, sobre todo, en comparación a la densa y nutrida cotidianidad que los puso en contacto-, tal constituye uno de los puntos medulares de la configuración relacional de los maestros. Y en este ámbito resulta similar la experiencia de los maestros de la ciudad y los de la campaña.

\section{Maestros, sacerdotes, jueces de paz}

No obstante las reformas implementadas a fines del periodo virreinal y con el gobierno de Martín Rodríguez, no hay dudas acerca del papel central que los clérigos tuvieron en la constelación de autoridades del periodo (Barral, 2007; Di Stefano, 2004). No faltan textos que dan por descontado que los sacerdotes mantenían una estrecha articulación con la enseñanza. Ahora bien, ¿cómo eran esos vínculos? ¿Cuál fue el papel que desempeñaron en la enseñanza elemental?

Un retrato acerca del modo en que los sacerdotes de la ciudad fueron vinculados a las escuelas es referido - para un periodo más temprano que el que aquí se trabaja- en el diccionario biográfico de Avellá (1983). El autor indica que Francisco Javier Dicido y Zamudio en 1773 construyó una "escuela pública, donde se enseñan las primeras letras a la juventud"

\footnotetext{
${ }^{19}$ Sala X-6-2-4, AGN, Buenos Aires.
} 
de la parroquia de la Piedad (Avellá, 1983: 102). En 1813, en San Isidro, el presbítero BartoIomé José Márquez actuaba como cura y colaboró en la puesta en marcha de una escuela para niñas. ${ }^{20}$ Años después, cuando el Departamento de Primeras Letras crecía, el rector Antonio Sáenz recuperó esa experiencia, elogió la tarea del cura y llevó adelante gestiones para colaborar en la financiación del proyecto. Provisoriamente, se le asignó una dotación similar a la de los maestros y se le pasó informe, vía el ministro de gobierno, a la Sociedad de Beneficencia. ${ }^{21}$

Y, efectivamente, hubo sacerdotes que actuaron como maestros. En algunos casos se trató de regulares secularizados, o bien de tenientes de cura que se abocaron a la enseñanza. 22 Pero la evaluación del conjunto sugiere que los sacerdotes consideraron que estaban sobrecargados de tareas o actividades como para agregar horas de clase frente a alumnos. Sí, generalizadamente, se inmiscuyeron en el visado de la escuela y el desempeño de los maestros. Tal característica fue extensiva a las regiones rurales. Aunque pudo haber conflictos entre sacerdotes y maestros, el conjunto no ofrece un esquema de recurrente oposición. ${ }^{23}$

En cuanto a la participación de hombres formados para servir en la Iglesia y que se desempeñaron en la gestión de escuelas, cabe distinguir a buena parte del elenco que manejó la Universidad de Buenos Aires y su Departamento de Primeras Letras. Allí estuvieron Antonio Sáenz, Juan Manuel Fernández Agüero, Antonio de Ezquerrenea y, sobre todo, Saturnino Segurola. Este último había nacido en Buenos Aires en 1776, se formó en el Colegio de San Carlos y en la Universidad de San Felipe, en Chile. Doctorado en teología, fue ordenado presbítero. Además de estar a cargo de la Biblioteca de Buenos Aires y de la difusión de la vacuna, fue inspector general de escuelas; primero, durante unos pocos meses, entre 1818 y 1819, y luego por un extenso periodo comprendido entre 1828 y 1852. Poco después de dejar el cargo, falleció.

En la campaña, el párroco o algún teniente de cura tenía un lugar destacado en el seno de las juntas protectoras que administraban las escuelas. Éstas eran usualmente presididas por los jueces de paz y completadas con uno o dos vecinos. ${ }^{24}$ Se trata de una composición

\footnotetext{
${ }^{20}$ Como maestro, colocó a Basilio Antonio García, quien, a la postre, sería capellán del fuerte de Rojas y, en la década de 1830, cura de Morón.

${ }^{21}$ Sala X-6-2-4, AGN, Buenos Aires.

${ }^{22}$ En agosto de 1828, por ejemplo, el cura párroco de Monte, Santiago Salas, fue postulado como maestro. En Ensenada, el cura ofició de suplente de un maestro que había renunciado. O, en 1830, Juan Manuel Aparicio en Pergamino. Expedientes 491, 707 y 746, legajos 5, 8 y 9, DGE, AHPBA, La Plata.

${ }^{23}$ Son rasgos parecidos - en la medida de lo comparable - a lo que William Taylor ha descrito para las diócesis de Guadalajara y México. Allí, el maestro de escuela era subalterno del sacerdote (Taylor, 1999: 493). No así en el caso de Francia que estudió Eugene Weber a fines del siglo XIX, donde, entre sacerdotes y maestros, se dio una férrea competencia (Weber, 1976: 303 y ss.).

${ }^{24}$ Una copia impresa del reglamento para las juntas protectoras se encuentra en legajo 156, Sala X-6-1-1, AGN, Buenos Aires.
} 
colegiada, a través de la cual se vislumbraban conflictos o discusiones que en la ciudad —bajo la presencia más cercana de las autoridades que dirimían en última instancia los conflictosaparecen opacados.

El papel de los sacerdotes en la campaña se ilustra con las intensas participaciones de José Miranda en San Antonio de Areco; a Francisco de Paula Robles en Chascomús; o Laureano Ansoategui en San Pedro, y Santiago Rivas en Quilmes. Para ejemplificar el interés y el modo en que estos vínculos sucedían, puede referirse al cura Pedro José Crespo, quien oficiaba en Baradero. Allí, entre 1825 y 1828, actuó como maestro Gerónimo Berdeal. En 1828, Berdeal renunció al cargo, y al hacerlo protestó contra la junta protectora del lugar, indicando que no se le proveían los útiles correspondientes y le faltaba apoyo para afianzar la educación entre los padres. La respuesta de Crespo no se hizo esperar, y puede dividirse en tres partes: criticó duramente al maestro — tildándolo de borracho, de tratar "solamente con gentes de baja esfera" y de haber abandonado la escuela-, señaló que el juez de paz no cumplía su parte en lo concerniente a la escuela ${ }^{25}$ y apuntaló la candidatura de Mateo Muhiños para reemplazar al renunciante. ${ }^{26}$ Saturnino Segurola, desde la inspección general de Buenos Aires, buscó una salida alternativa y le propuso a Crespo hacerse cargo de la escuela, ${ }^{27}$ quien no aceptó y logró, tras insistir, que Muhiños tomara el cargo, pero al poco tiempo renunció.

Los jueces de paz también tuvieron un papel clave. Para los maestros, un buen vínculo con ellos condicionaría sus desempeños. Aquí se presenta un ejemplo del modo en que, desde un juzgado, se influyó para que el maestro fuera cesado. En noviembre de 1826, el juez de paz de la Guardia del Monte, Vicente González, se quejaba de la falta de adelanto de la escuela. Tras esas referencias, en el juzgado recibieron la requisitoria para que el maestro (Francisco Alargón) asistiera, durante los meses de enero y febrero, a la capital "con el fin de concurrir a la academia teórico-práctica de sistema de mutua enseñanza". Allí partió el maestro. Mientras Alargón permanecía en la ciudad, se profundizó la crítica al maestro, y el nuevo juez de paz, Juan Zenón Videla, escribió elogiando las medidas que el gobierno había tomado en materia educativa, pero continuó sus reproches al maestro. Al hacerlo, Videla pidió que se aprovechara la estancia de Alargón en Buenos Aires para que fuera reemplazado. Antonio de Ezquerrenea - que ocupaba el cargo de vicerrector o prefecto del Departamento de Primeras Letras- desestimó el pedido. Cuando Alargón volvió a Monte, los problemas se crisparon. ${ }^{28}$ Según el maestro, apenas arribó desde la capital:

\footnotetext{
${ }^{25}$ Crespo, al referirse al juez de paz, en su dedicación a la escuela, indica: "no tiene antecedentes ningunos relativos al cumplimiento de su deber, y solo por la arbitrariedad con que quiere proceder prevalido de la autoridad para satisfacer pasiones bajas, e innobles". Expediente 429, legajo 5, DGE, AHPBA, La Plata.

${ }^{26}$ La información se recupera de los expedientes 422, 425, 428 y 429, legajo 5, DGE, AHPBA, La Plata.

27 Expediente 422, legajo 5, DGE, AHPBA, La Plata.

${ }^{28}$ Sala X-6-2-5, AGN, Buenos Aires.
} 
me hallaba a la puerta de mi casa y pasando el Sor. Juez Presidente de la Junta Inspectora a caballo me llamó como a diez pasos fuera de ella, interrogándome a quién me había presentado y si mi llamada había sido para examen, contesté a lo primero que en aquel momento acababa de llegar y que mi llamada no había sido para examen, pues hacía cerca de dos años lo había sido. Enseguida me previno que al siguiente día me presentase a la estancia de su habitación cerca de una legua de aquel destino á responder a preguntas de idoneidad concernientes á mi ejercicio, á lo que consté que en primer lugar no tenía caballo, y en segundo ya había sido examinado. ${ }^{29}$

En virtud de la contestación, el juez de paz lo amenazó con el cepo, para luego anunciarle que quedaba en "suspenso de su servicio". En el oficio que elevó al inspector de Educación, el juez de paz añadió que Alargón estaba poseído por el "odioso vicio de la embriaguez". Ezquerrenea expresó que el preceptor podía haberse emborrachado alguna vez, pero se había demostrado con relativa idoneidad en el desempeño de su tarea, ante lo que se puso en cuestión lo dicho por el juez de paz.

Como consecuencia de la diferencia de opiniones, se le solicitó a Ramón Amoroso, una de las autoridades del poblado de Chascomús, que lleve adelante una indagatoria. ${ }^{30}$ Todos los testimonios que recogió indican que vieron ebrio al maestro, profiriendo palabras ofensivas y "tramando quimeras". ${ }^{31}$ En marzo de 1827, Alargón fue destituido. En enero de 1828, el establecimiento de la guardia se encontraba destrozado y abandonado, por lo que un grupo de padres elevó un oficio, señalando con pesar que habían dejado que se destituya a Alargón y, su reemplazante, abandonó el cargo apenas había arribado al destino. ${ }^{32}$ Esos padres no dudaron en sugerir que la afición a la bebida de Alargón no era tan grave, que probablemente se había ya enmendado y que sería buena resolución volver a contratarlo. La moción no tuvo respuesta y en los siguientes dos años pasaron por la escuela cuatro preceptores (Juan Bermúdez, Vicente González, Vicente Morales y Francisco Quintana), ninguno de los cuales llegó a permanecer más de unos pocos meses.

Y si hubo autoridades locales que se involucraban activamente en el devenir de la escuela, no faltaron funcionarios que las ignoraron. En abril de 1827, el maestro Antonio Ruiz de Guzman arribó a Morón. Fue a la casa del juez de paz con el pliego de su designación, mas no lo pudo hallar. Sólo tras varios intentos logró que un delegado del juez de paz recibiera su pliego y le entregara las Ilaves de la escuela.33

\footnotetext{
29 Sala X-6-2-5, ACN, Buenos Aires.

30 Sala X-6-2-5, ACN, Buenos Aires.

${ }^{31}$ Expediente 371, Legajo 4, DGE, AHPBA, La Plata.

32 Expediente 441, legajo 5, DGE, AHPBA, La Plata.

${ }^{33}$ Sala X-6-2-5, AGN, Buenos Aires.
} 
Si los maestros tuvieron conflictos con las juntas protectoras de la campaña, entre éstas y los funcionarios radicados en la ciudad también hubo momentos de tensión. En la crítica situación que describió Valentín Gómez -y que llevó a la separación del Departamento de Primeras Letras de la Universidad_, resaltó las quejas por la insubordinación de las juntas de la campaña. El oficio que elevó en diciembre de 1827 indicaba:

\begin{abstract}
Las juntas inspectoras son generalmente omisas; contribuye a esto la calidad de los individuos que las componen y particularmente su residencia a grandes distancias del lugar en que se halla la escuela. No hay gestiones que basten para empeñar a este objeto a los jueces de Paz. Además, convendría que cuando estos no residen en la población en que se halla la escuela, fueren nombrados los curas o tenientes en calidad de presidentes. ${ }^{34}$
\end{abstract}

Como fundamento de ello, el rector podría haber citado las numerosas circulares en las que se solicitan datos que nunca eran devueltos por las juntas protectoras. En junio de 1827, por ejemplo, se pidieron informes sobre el número de niños que tenía a su cargo cada maestro, y desde veinte sitios no se le respondió al rector. No faltaron oportunidades en que se enviaron útiles y enseres para las escuelas que arribaron a sitios donde los ranchos de las escuelas estaban inutilizados. Incluso hubo un caso en Chascomús en que la habitación del maestro fue puesta a disposición de una sociedad ilustrada que, con su ocupación, obstaculizaba la escuela (Bustamante, 2007a: 107 y ss.). Desde el punto de vista de los funcionarios locales, el asunto se apreciaba con otro sentido.

En agosto de 1828, el juez de paz Luciano Ortega de San Vicente le recriminó al inspector general la insistencia con que se le solicitaban informes. Indicó:

\footnotetext{
El Señor Inspector cree, o al menos se lo persuade, que el Presidente de esta escuela [el propio juez de paz] no tiene aptitudes para espedirse como debe, y que por lo mismo se le puede reconvenir con repetición sin temor alguno, en cuyo caso, al que subscribe se le ha de permitir exponer, que se ha equivocado muy mucho, el Señor Inspector. ${ }^{35}$
}

En la ciudad, los vínculos entre autoridades y maestros recorren un camino diferente. Asentadas allí las autoridades más importantes de la emergente burocracia educativa, la resolución de los problemas - que seguramente los hubo- encontró respuestas que no han dejado una huella significativa en los archivos. La efervescencia que se distingue en las discusiones entabladas en torno a las juntas protectoras de la campaña contrasta con los pocos datos que

\footnotetext{
${ }^{34}$ Sala X-6-2-5, AGN, Buenos Aires.

${ }^{35}$ Expediente 490, Legajo 5, DCE, AHPBA, La Plata [subrayado en el original].
} 
se recuperan de la ciudad. Mientras que acerca de los pueblos los casos podrían multiplicarse, sobre los vínculos desenvueltos en la ciudad, el asunto es más difícil de reconstruir. Allí, sólo afinando la mirada y orientando la perspectiva sobre escuelas que no eran financiadas por el Estado, se reconocerían algunos de estos entramados. En agosto de 1828, el inspector Saturnino Segurola fue reconvenido por el ministro Roxas y Patrón, en virtud de la desafección de un preceptor particular. Segurola explicó al respecto: "ha hecho cerrar la escuela particular que tenía el portugués Barboza en el barrio del Hospicio [...]. Hubo un informe del juez de paz, pero no se la cerró". Tras nuevos informes sobre su "continua embriaguez", entonces sí Segurola resolvió cerrarle la escuela. ${ }^{36}$ Ante ello, el ministro indicó que no estaba en las facultades del gobierno "privar a un individuo de un ramo de industria, como es el de la enseñanza, cuyo ejercicio es libre en el país". Según Roxas y Patrón, Segurola se debería haber limitado a informar a la autoridad competente. El caso, aunque no pueda generalizarse, es interesante; permite mostrar que, en la configuración de relaciones tejidas en la ciudad, además de las autoridades de la inspección general de escuelas, podían tomar parte miembros del gobierno. Pero, en contrapartida, el elenco de involucrados en las juntas protectoras de la campaña no tiene presencia.

\section{La Academia de Preceptores}

Durante la década de 1820, las figuras pedagógicas más prominentes de Buenos Aires estuvieron ligadas al sistema de enseñanza mutua. James Thompson estuvo en el Río de la Plata entre 1819 y $1821 .{ }^{37}$ Instaló una escuela desde la que transmitió el sistema. Sin embargo, con su partida hacia Chile, en 1821, la propagación se vio limitada. La difusión del método cobró nuevos bríos entre con la designación de Pablo Baladía. Este emigrado español fue contratado por el gobierno rivadaviano para instalar una "Escuela o Academia de Preceptores”. ¿Cómo impactó esa institución? Aquí, además de describir el modo en que desarrolló sus actividades, interesa destacar las legitimaciones que supuso y las reacciones que generó entre los maestros. ${ }^{38}$

Baladía arribó a Buenos Aires en 1825. En diciembre de ese año fue disignado director de escuelas. Con ese cargo debería establecer escuelas en los cuarteles para instruir a la tropa, inspeccionar establecimientos educativos y dirigir una escuela normal, cuyo propósito

\footnotetext{
${ }^{36}$ Sala X-6-1-6, AGN, Buenos Aires.

37 James Thompson viajó desde Inglaterra con el propósito de impulsar el sistema de enseñanza mutua en Latinoamérica.

38 Un análisis de las características pedagógicas y políticas que supuso la implementación del método en Buenos Aires se halla en Narodowski (1994).
} 
sería "formar un plantel de preceptores". ${ }^{39}$ A fines de 1826 se le reafirmó como director general de Educación, desde entonces "en propiedad" del cargo. ${ }^{40}$ En junio de 1827, el maestro Francisco Juárez, primero, y Lucas Fernández, poco después, lo suplantaron en su cargo de la normal, mientras Baladía continuaba como autoridad estatal —con menores atribuciones. ${ }^{41}$ En septiembre elevó un oficio que indicaba que no continuaría sus inspecciones, en tanto el gobierno resolviese el pedido que algunos maestros habían hecho para que cesara en su cargo. A fines de 1827, había sido cesado.

En el breve periodo en que actuó como funcionario de Estado, Baladía participó de significativas políticas en relación con los maestros. Apenas tomó su cargo, visó cuestiones de índole cotidiana —el surtido de agua para las escuelas, por ejemplo—, presentó un reglamento para las escuelas ${ }^{42}$ y trató de arreglar lo que necesitaría para la apertura "de la Normal de Enseñanza Mutua". ${ }^{3}$ Ésta funcionó en los meses de enero y febrero, pero hay noticias que aluden al dictado de turnos en horario vespertino a lo largo de 1826. En tal sentido, Baladía refirió a la necesidad de contratar un portero y ser aprovisionado de velas. ${ }^{44}$ Probablemente en el invierno o primavera concurrieron los maestros de la ciudad, mientras que entre enero y febrero de 1826 y 1827 fueron conminados - y convencidos - a asistir los maestros de la campaña. ${ }^{45}$

Los cursos se dictaron en un edificio ubicado en el barrio de la Merced. Las materias incluían aspectos generales sobre cómo poner en marcha una escuela bajo el sistema de enseñanza mutua, los enseres que se debían emplear, las características de los textos que recomendaba, el modo en que se debían administrar los aspectos disciplinares. Junto a ello

${ }^{39}$ El decreto del Departamento de Gobierno, fechado en 6 de diciembre de 1825, no fue publicado en el registro oficial, sino dado a conocer a través de la prensa núm. 6 (1825, 6 de diciembre). El Mensajero Argentino 1825-1827, tomo II. Buenos Aires: Imprenta del Estado.

${ }^{40}$ Nombrando director general de Escuelas en propiedad, á D. Pablo Baladia - Atribuciones del mismo (1826, 13 de diciembre). Registro Oficial de la República Argentina que comprende los documentos espedidos desde 1810 hasta 1873. tomo segundo 1822 á 1852. Buenos Aires: La República - Imprenta Especial de Obras.

${ }^{41}$ Expediente 353, Legajo 4, DGE, AHPBA, La Plata.

42 Además de Narodowski (1999), véase López (1997).

${ }^{43}$ Sala X-6-2-4, AGN, Buenos Aires.

${ }^{44}$ En mayo de 1826, el prefecto Antonio de Ezquerrenea pidió permiso para gastar seis libras de velas por noche, comprar "tres arañas ordinarias de hoja de lata, con todo lo preciso para colgar en aptitud de bajar, y subir según sea preciso, y tres docenas de cornucopias". Sala X-6-2-4, AGN, Buenos Aires. La necesidad del portero fue justificada por Baladía con el propósito de guardar el orden en el entrar y salir, al abrir las puertas en horas fijas, "para que se custodien debidamente los capotes y sombreros de los alumnos, para que se franquee o niegue la entrada a quienes corresponde". Sala X-6-2-4, AGN, Buenos Aires.

${ }^{45}$ En noviembre de 1825, Antonio de Ezquerrenea redactó una circular indicando que "ha prevenido se pongan en vacaciones por los dos meses próximos de enero y febrero del año entrante de 1826: para que así se haga más llevadero en unos y otros, aquella extraordinaria dedicación". Sala X-6-2-4, AGN, Buenos Aires. 
se enseñó cómo trabajar con formularios que permitirían homogeneizar el seguimiento de los alumnos y la gestión de la escuela. En total comprendían 54 materias. ${ }^{46}$

No se sabe con exactitud cuántos maestros pasaron por dichos cursos, pero no fueron pocos. ${ }^{47}$ Además, se presentaron interesados que, tras el curso, se postularon como preceptores. El antecedente acreditó cierta pericia. Genaro Damico, por citar un ejemplo, en 1826 se candidateó para cubrir una vacante y, además de referencias sobre su conducta, adjuntó una evaluación que le había expedido Baladía, quien afirmaba que Damico "es apto para la enseñanza según el método de enseñanza mutua", y aunque le faltara algo de perfección la acabaría de adquirir en la propia academia a la que "ha asistido hasta hoy con la mayor puntualidad". 48

Si la Academia marcó un punto de referencia para quienes asistieron, también lo hizo para quienes no participaron. En enero de 1827, Valentín Gómez le aceptó la renuncia al preceptor de la villa del Luján, Juan Luis Ramírez. ${ }^{49}$ El preceptor explicó que estaba en el puesto desde hacía varios años, sin "que por mi parte haya dado la más pequeña nota de mi conducta pública ni privada"; tal habría sido su compromiso que, incluso, algunas veces debió abandonar sus "sagradas obligaciones como padre" para atender los deberes de la escuela. Añadía, justificando su renuncia, que no se encontraba bien de salud y perdía su vista. A pesar de la dificultad por conseguir buenos maestros reemplazantes, el rector aceptó el alejamiento de Ramírez sin inconvenientes y, al pasar, resaltó que el referido maestro se había "resistido" a la Academia.

A fines de 1827, cuando el rector de la universidad cesó las actividades de la universidad, en relación con las primeras letras, detalló distintas circunstancias, entre las cuales indicó que los maestros habían manifestado una notoria insubordinación frente a Pablo Baladía. Incluso aludió a un "motín" o una "imposición audaz" contra aquél. ¿Qué llevó a tal posición? Se criticó a Baladía por su condición de español, ${ }^{50}$ pero el nudo de la reprobación de los preceptores de la ciudad habría estado dado por sus opiniones sobre el manejo de los recursos.

En la crítica coyuntura financiera generada por la guerra con Brasil y la devaluación del papel moneda, los salarios de los maestros se depreciaron. Ante esa situación, el gobierno le pidió a Baladía un informe acerca de cómo redistribuir los recursos que se asignaban a las escuelas y, en esas mismas semanas, se dio a conocer el caso de un maestro que buscó

${ }^{46}$ Sala X-6-2-4, AGN, Buenos Aires.

${ }^{47}$ Dos detalles sobre la concurrencia a la Academia. Sobre los maestros de la campaña cabe acotar lo significativo que resulta que la orden de que asistieran haya sido efectivamente cumplida (lo cual no es un detalle menor). Por otro lado cabe notar que a pesar de que la Sociedad de Beneficencia tuvo estrechos vínculos con el sistema de enseñanza mutua, todo parece indicar que no concurrieron mujeres a estos cursos.

48 Sala X-6-2-5, ACN, Buenos Aires.

49 Sala X-6-2-5, ACN, Buenos Aires.

${ }^{50}$ En 1826, sin embargo, Baladía había tramitado y obtenido la carta de ciudadanía por parte del gobierno. Véase al respecto Sala X-6-2-4, ACN, Buenos Aires. 
complementar su sueldo con el dictado adicional de clases particulares a algunos de sus propios alumnos de la escuela pública. En respuesta a ambos casos, Baladía elevó informes compuestos por soluciones alternativas. Y tras algunas consideraciones contemplativas, no dudó en afirmar que el cobro de lecciones adicionales constituía una defraudación al Estado y a los intereses públicos. Asimismo, al ser consultado sobre los medios de redistribuir recursos, sugirió diversos arbitrios, entre los que destacó la posibilidad de clausurar algunas escuelas. Cerraría las de San Nicolás, Merced y Concepción, que tenían alrededor de veinte, sesenta y ciento veinte alumnos, respectivamente. Estos niños pasarían a las escuelas ubicadas a varias cuadras de distancia y sus maestros verían algo aumentados sus ingresos. ¿Qué sucedería con los preceptores cesados? Según Baladía, ellos no tendrían por qué preocuparse, la disponibilidad de plazas era frecuente y no extrañaría que a los pocos meses los interesados pudieran retomar la actividad.

Un tercer punto crítico entre los preceptores y Baladía se vinculó a la presencia o no de ayudantes rentados. Mientras que Baladía los desaconsejó, el grupo de preceptores de la ciudad que se le enfrentó manifestó:

Los Preceptores de las Escuelas Públicas de Primeras Letras que tenemos el honor de suscribir con la mayor consideración hacemos presente a Ud.: que el número excesivo de alumnos de que se hallan recargadas nuestras Escuelas exige con precisión un Ayudante, pues sin éste es imposible que ningún Preceptor pueda debidamente desempeñar con el número de 100 niños en los distintos ramos..$^{51}$

La crítica no finalizaba allí. Los maestros reprobaban uno de los puntos medulares por los que se pretendía difundir el sistema de enseñanza mutua:

se dice que el método de Lancaster proporciona que un solo Maestro dirija 500 niños, ésta es proposición que sólo hemos oído que se dice, pero en la práctica que hemos tocado se ha visto todo lo contrario; pues cuando se instituyó dicho método en esta ciudad por el inglés Don Diego Tonson [sic] vimos que diariamente nos juntábamos seis a dirigir la escuela, que no pasaba de 100 alumnos [...] y sin embargo jamás se vieron los progresos que se anunciaron ¿qué será de un solo Maestro, y con número superior?52

En septiembre de 1827, la situación de Baladía parecía tan débil como la del gobierno de Rivadavia. Aquél decidió suspender sus inspecciones a las escuelas, en tanto no se resolviera su

\footnotetext{
${ }^{51}$ La nota estaba firmada por los maestros Jose Ocantos, Francisco López, Tomás Julián Ortiz, Pedro Golero, Francisco Juárez, Mariano Canavers, Justo Jose Díaz Gómez. Sala X-6-1-1, AGN, Buenos Aires. En 2005, este oficio se encontraba resguardado en el expediente citado, pero en una posterior consulta realizada en 2015, ya no se hallaba allí (en el transcurso de estos años, además, este legajo fue foliado).

52 Sala X-6-1-1, AGN, Buenos Aires.
} 
idoneidad a cargo del ramo..$^{53}$ No sólo fue cesado, ${ }^{54}$ sino que, al calor de esa separación, el rector Valentín Gómez llevó adelante la desmembración del Departamento de Primeras Letras de sus incumbencias.

El detenimiento en torno a lo sucedido con Baladía y la Academia de Preceptores permite atender a un curioso momento — que no se repetiría en la primera mitad del siglo XIX — en que algunos de los maestros accedieron a una instancia de acreditación de su ocupación. Pero, además, generaron las condiciones para que se visualizaran y actuaran como grupo.

El conjunto muestra un proceso sucedido en Buenos Aires, en el que participaron muchos de los maestros de la campaña: fueron instados a trasladarse a la ciudad y consiguieron permiso para que sus escuelas estuvieran durante varias semanas cerradas (lapso que, no casualmente, coincidía con la siega y en que la asistencia de alumnos mermaba). No faltaron, se ha mencionado, educadores que desestimaron su concurrencia a los cursos de la Academia. Pero quienes sí lo hicieron no parecen haber manifestado críticas acerca de las propuestas de Baladía. Tampoco se han podido recuperar datos que refieran a lazos o vínculos entre estos maestros.

\section{Conclusiones}

El nudo de la perspectiva ha estado afirmado en los maestros de la ciudad y la campaña de Buenos Aires. Se ha dirigido una mirada en la que ellos son integrados al contexto en que desenvolvieron sus tareas, describiendo distintos escenarios en que se encontraron inmersos. Como producto del acercamiento, no se ofrece un patrón o modelo de interrelación, sí una serie de vértices en los que se apuntala el conjunto. Y, en tal marco, la conceptualización afirmada en la noción de "configuración escolar" cobra sentido. La cartografía que se traza a partir de los vínculos en que se encontraban los maestros en la década de 1820 tuvo entre sus puntos de referencia a sacerdotes, jueces de paz, autoridades estatales, vecinos.

La constelación de actores involucrados cobraría mayor densidad. Cabría aludir a los nexos desenvueltos entre los maestros y sus familias, o sus colegas mujeres, por referir importantes grupos sociales sobre los cuales poco se ha hablado. También se anhelaría reconocer el modo en que los alumnos consideraban a sus maestros. Un desafío adicional - sin dudas sugerentesupondría reconstruir algunas de las redes en las que se involucran las interdependencias aquí

\footnotetext{
53 Indicó Baladía: "sabedor el que suscribe de que algunos Preceptores han representado al Gobierno en solicitud de que se [me] destituya de la Dirección general de escuelas, hago presente suspender visitas de inspección hasta que la superioridad se digne resolver sobre dicho negociado. El Director cree de su deber decirlo al Sr. Inspector general del Departamento esperando tenga a bien aprobar esta conducta". Sala X-6-2-5, AGN, Buenos Aires.

${ }^{54}$ Hacia 1830 Baladía regenteaba una escuela particular. Expediente 143, Sala X-6-1-2, AGN, Buenos Aires.
} 
presentadas. Lo compartido se entrelaza (y en no poca medida se limita) con las posibilidades recogidas en las fuentes tomadas en cuenta.

En este texto se han mostrado algunas de las formas en que los padres o madres consideraban el modo en que los maestros debían vincularse con los alumnos. Ha referido un lugar secundario para los sacerdotes, en relación con la enseñanza elemental, pero central en la gestión de las escuelas. Se ha descrito a los jueces de paz y las autoridades estatales en relación con la administración escolar, sugiriendo que ninguno de estos funcionarios resolvió autónomamente el devenir de las escuelas. El modo en que el rector de la universidad o sus allegados ceden ante distintas circunstancias muestra tal límite. En el recorrido, además, se atendió a lo acontecido con la Academia de Preceptores. Lo sucedido en el marco de esa experiencia ha permitido evaluar instancias de legitimación o acreditación, así como coyunturas en las que los maestros de escuelas de la ciudad se identificaron en tanto grupo.

El desarrollo de las escuelas en la década de 1820 permite considerar los cambios sociales que conllevó la emergencia de una alternativa laboral — ser maestro de escuela-, lo cual no había tenido tal presencia en el periodo virreinal. Anteriormente hubo maestros ligados a corporaciones o emprendimientos particulares, sin embargo, el número de establecimientos financiados en el periodo posindependiente alteró el horizonte de la ocupación. Y en ese proceso de cambio se ha buscado mostrar cómo los maestros se insertaron en la sociedad rioplatense.

\section{Fuentes}

Archivos

Archivo General de la Nación, Buenos Aires (Argentina), Sala X.

Archivo Histórico de la Provincia de Buenos Aires (AHPBA), La Plata (Argentina), Dirección General de Escuelas.

Hemerografía

El Mensajero Argentino. 1825-1827, tomo 2, Imprenta del Estado, Buenos Aires.

Registro Oficial de la República Argentina que comprende los documentos espedidos desde 1810 hasta 1873. tomo segundo 1822 á 1852, La República-Imprenta Especial de Obras, Buenos Aires.

\section{Bibliografía}

Aliata, Fernando (2006), La ciudad regular, Universidad Nacional de Quilmes, Bernal.

Avellá Cháfer, Francisco (1983), Diccionario biográfico del clero secular de Buenos Aires, t. 1, 1580-1900, Francisco Avellá Cháfer-Arzobispado de Buenos Aires, Buenos Aires. 
Barral, María Elena (2007), De sotanas por la pampa: religión y sociedad en el Buenos Aires rural tardocoIonial, Prometeo, Buenos Aires.

Bustamante Vismara, José (2007a), Las escuelas de primeras letras en la campaña de Buenos Aires (18001860), Archivo Histórico "Ricardo Levene"-Instituto Cultural de la Provincia de Buenos AiresAsociación Amigos del Archivo Histórico, La Plata.

Bustamante Vismara, José (2007b), "Buscando los maestros perdidos (campaña de Buenos Aires, 1800-1860)", Historia de la Educación. Anuario, núm. 8: 217-239.

Elias, Norbert (1993), La sociedad cortesana, Fondo de Cultura Económica, Madrid.

Elias, Norbert (1984), El proceso de la civilización, Fondo de Cultura Económica, México.

Di Stefano, Roberto (2004), El púlpito y la plaza. Clero, sociedad y políica. De la monarquía católica a la república rosista, Siglo XXI, Buenos Aires.

Fradkin, Raúl (2008), iFusilaron a Dorrego! O cómo un alzamiento rural cambió el rumbo de la historia, Sudamericana, Buenos Aires.

García Belsunce, César (dir.) (1979), Buenos Aires 1800-1830. Educación y asistencia social, t. 3, Ediciones del Banco Internacional y Banco Unido de Inversión, Buenos Aires.

López, Claudina María (1997), "La educación escolar en el siglo xIX: el caso del reglamento de enseñanza mutua de Pablo Baladía", Universidad Nacional del Centro de la Provincia de Buenos Aires, Tandil, tesis de licenciatura.

Martínez Boom, Alberto y José Bustamante Vismara (2014), "Introducción. Un tema con variaciones", en Escuela pública y maestro en América Latina. Historias de un acontecimiento, siglos XVIII-XIX, PrometeoUniversidad Pedagógica Nacional, Buenos Aires, pp. 21-30.

Newland, Carlos (1992), Buenos Aires no es pampa. La educación elemental porteña 1820-1860, Grupo Editor Latinoamericano, Buenos Aires.

Narodowski, Mariano (1994), "La expansión del sistema lancasteriano. El caso de Buenos Aires", Anuario IEHS, núm. 9: 255-277.

Narodowski, Mariano (1999), Infancia y poder. La conformación de la pedagogía moderna, Aique, Buenos Aires.

Rockwell, Elsie (2018), Vivir entre escuelas: relatos y presencias. Antología esencial, selección y estudio preliminar a cargo de Nicolás Arata, Carlos Escalante y Ana Padawer, Clacso, Buenos Aires.

Rockwell, Elsie (2007), Hacer escuela, hacer Estado. La educación posrevolucionaria vista desde Tlaxcala, El Colegio de Michoacán-Cinvestav-CIESAS, México.

Roldán Vera, Eugenia (2014), "¿Maestro, preceptor o profesor? La denominación del docente de primeras letras en la Ciudad de México, 1750-1850", en A. Civera Cerecedo, C. Escalante Fernández y E. Rockwell (comps.), Sujetos, poder y disputas por la educación: textos de historiografía de la educación latinoamericana, El Colegio Mexiquense-Universidad Pedagógica Nacional-Centro de Investigación y de Estudios Avanzados del Instituto Politécnico Nacional, Zinacantepec, México, pp. 1337-1349.

Taylor, William (1999), Ministros de lo sagrado. Sacerdotes y feligreses en el México del siglo XVIII, vol. 2., El Colegio de México-Secretaría de Gobernación, Subsecretaría de Asuntos Religiosos-El Colegio de Michoacán, México.

Ternavasio, Marcela (2002), La revolución del voto. Revolución y elecciones en Buenos Aires, 1810-1852. Siglo XXI, Buenos Aires.

Weber, Eugene (1976), Peasants into Frenchman: The Modernization of Rural France, 1870-1914, Standford University Press, Standford.

José Bustamante Vismara es doctor en Historia, investigador del Consejo Nacional de Investigaciones Científicas y Técnicas (Conicet), y docente del Departamento de Historia 
de la Universidad Nacional de Mar del Plata, Argentina. Sus temas de investigación están ligados a la historia de la educación hispanoamericana en el siglo XIX. Entre sus publicaciones recientes se cuentan "Construcción estatal y desarrollo escolar (Córdoba, Buenos Aires y Entre Ríos, 1820-1850)", Historia de la Educación. Anuario, vol 17, núm. 1, 2016: 50-71; Escuela pública y maestro en América Latina. Historias de un acontecimiento, siglos XVIII-XIX (Alberto Martínez Boom y José Bustamente Vismara, comps.), Prometeo-Universidad Pedagógica Nacional, Buenos Aires, 2014, y Escuelas en tiempos de cambio: política, maestros y finanzas en el Valle de Toluca durante la primera mitad del siglo XIx. El Colegio de México, México.

Recibido: 18 de septiembre de 2017

Aceptado: 4 de marzo de 2018 